\title{
¿El hombre nace bueno o nace malo? Distintas concepciones
}

\section{Is man born good or born bad? Different conceptions}

Rocael Paiz Varela Universidad de San Carlos de Guatemala Maestro en Filosofía

rpaiz@fahusac.edu.gt https://orcid.org/0000-0003-0528-486

\section{$\triangle$ Referencia del ensayo}

Paiz Varela, R. (2021). ¿El hombre nace bueno o nace malo? Distintas concepciones. Revista Guatemalteca de Cultura. 1(1), 27- 35. DOI: 10.46954/revistaguatecultura.v1i1.3

Recibido 15/09/ 2020

Aceptado 25/01/2021

\section{Resumen}

Afirmar que el hombre desde su concepción es bueno no es incorrecto ni supone estar equivocado. Tampoco sostener que el hombre nace malo representa una negación de la realidad. Sin embargo, distintas corrientes de pensamiento han vivido en una confrontación por muchos años y se debaten entre lo bueno y lo malo que el hombre es en la naturaleza y, especialmente en la vida. Si el hombre nace bueno ¿por qué se encuentra incitado al mal? Y, si el hombre nace malo ¿por qué no puede redimirse y hacer el bien? Distintos filósofos y pensadores como Rousseau, Hobbes, Maquiavelo y Freud, así como otros, defienden variadas posturas y adoptan posiciones al respecto. ¿Nace el hombre bueno o nace malo? 
He aquí la importancia medular de este artículo que presenta un tema controversial en la historia del quehacer de la filosofía.

Palabras clave: hombre, naturaleza, bien, mal, albedrío.

\begin{abstract}
To affirm that man from his conception is good is not incorrect nor does it supposed to be wrong. Nor does the claim that man is born bad represent a denial of reality. However, different currents of thought have lived in opposition for many years and are debated between the good and the bad that man is in nature and, especially in life. If man is born good, why is he incited to evil? And if man is born bad, why can't he redeem himself and do good? Different philosophers and thinkers such as Rousseau, Hobbes, Machiavelli and Freud, as well as others, defend various positions and positions in this regard. Is the good man born or bad? Here is the central importance of this article that presents a controversial issue in the history of the work of philosophy.
\end{abstract}

Keywords: man, nature, good, bad, agency.

\section{Introducción}

Como profesor de cursos de filosofía me ha gustado originar entre mis estudiantes la controversia y la discusión sobre diversos temas filosóficos para que, por medio del análisis y la reflexión, unido a su modo particular de pensar -donde no dejan de intervenir la religión, las creencias, el medio social y la cultura-, puedan definir o puedan responderse a las interrogantes que se planten en la discusión de algunos temas afines en esos cursos.

Por tal razón me ha motivado el interés por despertar la curiosidad y el análisis, así como también la discusión seria para poder responder a la interrogante inicial de este tema y poder explorar las ideas y las posibles respuestas que se tengan o se aporten como intentos de definir -dentro de un clima de respeto a las creencias, costumbres y tradiciones- con criterio a la interrogante planteada.

¿Qué es el hombre?, ¿A qué vino y cuál es su objeto? Hay dos grandes días en la vida de una persona: el día en que nace y el día que descubre para qué (Valdez, 2021). ¿Es el hombre solamente un animal que ocupa la parte más alta en la escala biológica?, ¿es el hombre la creación más grande del reino animal?, ¿es el ser sublime que se enseñorea sobre todo lo creado o sobre todo lo existente?, 
o, ¿es el error más grande que la madre natura pudo haber cometido? Responder a estas interrogantes o intentar aclararlas de forma clara, precisa y concisa resulta una tarea que se coloca cuesta arriba ante las múltiples concepciones y pensamientos a través de la historia del pensamiento filosófico.

¿Qué es el hombre? Comúnmente podríamos decir que es un ser vivo que existe en la naturaleza y que se encuentra dotado, en su formación física o corpórea, de la capacidad de razonar, de pensar, de discernir, de reflexionar, de la capacidad de investigar, de manifestar expresiones de distinta índole, de hablar, de crear, de organizar, de decidir y de dirigir. También podríamos afirmar que es el animal más evolucionado y que se encuentra en la cúspide de la pirámide donde se ubican todos los animales que existen sobre la faz de la tierra.

En la historia de la filosofía no faltan respuestas a esta pregunta. ¿Es el hombre un animal político como suponía Aristóteles?, ¿Un animal que habla como él mismo decía?, ¿Un bípedo implume, como afirmaba graciosamente Platón?, ¿un animal razonable como pensaban los estoicos y después los escolásticos?, ¿un ser que ríe? (Rabelais), que piensa (Descartes), que juzga (Kant), que trabaja (Marx), que crea (Bergson)?; entre otras. Ni la suma de estas respuestas parece satisfactoria; puesto que son posiblemente demasiado amplias y a la vez estrechas. Además, una buena definición debe ser válida para todo el elemento definido, no siendo así en este caso (Comte, 2000).
Uno de los más grandes pensadores, filósofos y también uno de los creadores de la Enciclopedia, Diderot, esboza una definición que también puede ser discutible y que no puede tomarse sin meditación y sin análisis como verdadera: el ser humano está constituido por el sentimiento, eso, unido a la reflexión, debería estar en una escala arriba de todos los animales que existen y que puede regir, que actualmente vive en sociedad, que es capaz de practicar diversas ciencias y artes, que posee su propia concepción del bien y también del mal; el filósofo francés afirmaba que el hombre, quiera o no, se ha venido a constituir en un ser social.

Ahora bien, el hombre es un ser sociable desde el punto de vista biológico; se considera a este el grado supremo del desarrollo animal, con una conciencia más desarrollada, con un lenguaje articulado, con reacciones conductuales y sentimentales. El ser humano posee una conciencia, una razón y la capacidad de la religiosidad. La diferencia radical del hombre y el animal, es que este último se adapta a las condiciones por naturaleza mientras que el primero, crea herramientas para dominarla; el hombre no puede vivir separado de los demás (Rosental \& ludin, 1965).

De esta forma y de acuerdo con Marx, el hombre es un reflejo del producto del trabajo social. El hombre es un ser vivo con capacidad para razonar, hablar y fabricar objetos que le sean útiles, es un mamífero de la familia de los antropoides, de especie sapiens (Oxford, 2020). La filosofía griega entendía al hombre como un ser racional, que posee el logos, entendiendo al hombre como una cosa cuya 
naturaleza es entender las demás, se le conoce como una substancia racional a aquello que posee el hombre; el hombre es esencialmente dinámico. Para Platón, el alma del hombre tenía la capacidad de descender o ascender, de llegar a la semejanza con la divinidad o enajenarse de esta (Mora, 1979).

Santo Tomás de Aquino, afirmaba que el hombre también posee dos elementos; por un lado, el alma; por otro el cuerpo. El alma es el último de los espíritus creados, el cuerpo es la suprema cosa corpórea; presenta al hombre en la línea divisoria entre el espíritu y el cuerpo. Para los naturalistas, el hombre nace por un proceso lento y al azar, resultado de constantes evoluciones; ahora bien, para la Biblia, el hombre es la última creación de Dios, teniendo este todo planeado, siendo semejantes a su Dios, por ello son diferentes del resto de la creación (Utate, 2004).

\section{Contenido}

\section{¿Qué es el bien y qué es el mal?}

Preguntas sobre el origen del mal, del bien y de su concepción, siempre estarán presentes en la filosofía, ¿Qué representa el bien y el mal?; puede afirmarse que el bien está delimitado por la cultura. No existe el bien en un sentido general pues algo que se considera bueno en oriente pudiera ser completamente malo en occidente. Todo ello por la concepción cultural, para citar un ejemplo: los médicos consideran que salvar la vida es algo bueno, los kamikazes, en la segunda guerra mundial, creían que estrellar un avión contra blancos enemigos era honorable. Para muchas personas la compasión, la caridad y el amor es algo bueno; para los terroristas es bueno explotar una bomba en un colegio o en un centro comercial, explotar aviones contra las torres gemelas en los EEUU, Etc.

En el libro "Ética" se analiza que los filósofos griegos se preguntaban por la realidad de las cosas, pues las apariencias engañan; en esa línea de ideas llegaron a preguntarse sobre en qué consistía la verdadera noción de lo bueno. Basados fundamentalmente en los poemas de Homero, comenzaban pensando que lo bueno es lo que beneficia a la comunidad, siendo toda excelencia; entre más servicios prestaba el hombre a la comunidad, era más virtuoso (Cortina \& Emilio, 2008).

El termino bien, puede entenderse como una acción, una inclinación natural a fomentar aquello que es deseable, motivado por la comprensión de su entorno, de las personas y del ser mismo; opuesto al mal que es lo indeseable, relacionando el bien con la ética. La ética es la disciplina que estudia estos conceptos, relacionándose directamente con los fenómenos sociales; entonces el bien es aquello que se busca, que es aceptado por un estrato social, moral, digno.

En el diccionario de filosofía, el bien aparece como una luz, esta luz ilumina todo, de manera estricta es Dios; en sentido menos estricto, participa en él lo creado, incluso el hombre. Cuando la concepción se elabora filosóficamente, el bien se define como trascendental, convertible en el ser, con lo verdadero y con lo uno. Esta proposición, aunque parezca teológica es además metafísica. Casi de igual manera lo pensaba Kant, en efecto, si solo la voluntad puede ser llamada algo bueno, aparece el bien moral como un bien sumo (Mora, 1979). 
Conociendo un poco acerca del concepto del bien, puede abordarse al mal. Esto lleva al filósofo a cuestiones éticas, morales y de subjetividad. Cuando se piensa en el mal, en su esplendor, se piensa en fenómenos personales, sociales e históricos como asesinatos, violaciones, guerras y todos aquellos actos que se relacionan con lo siniestro; que emana de la propia perversión del ser humano.

Históricamente, se ha visto al mal como algo nacido de una fuerza diabólica, de lo sobrenatural, quizá porque el hombre no concibe tal maldad en sí mismo, de algo en la estructura genética, por el contrario. Existen las nociones de un Dios y un demonio, pero en el cristianismo no puede verse al demonio como un opuesto-igual a Dios; incluso el demonio fue creación de este último, y debido a la libertad, se ha corrompido (Carpintero, 2012).

Hobbes, en su libro Leviatán afirma que el hombre posee actitudes y atributos del mal; estos le impiden convivir armónicamente en la sociedad, que se convierte en su eterna vigilante. Afirma que en la naturaleza los seres humanos actúan de forma instintiva, negativa, egoísta y violenta; buscando únicamente su propio beneficio. Hobbes afirmaba que el hombre es egoísta por naturaleza, capaz de cualquier cosa incluso de matar para preservar su integridad; esta búsqueda del beneficio personal crea una situación caótica donde todos luchan contra todos.

En el pensamiento de Hobbes, el hombre es el enemigo del hombre, por ello, los seres humanos debieron formar una comunidad donde debe regular su conducta y sus intereses mediante las normas sociales; aceptando cada uno las reglas, solamente así se respeta la vida y las pertenencias. Cuando los seres humanos se agrupan, garantizan que no se vuelva a la situación primitiva (Gonzales, 2018).
El mismo autor indica que, al contrario de Hobbes, Rousseau afirma que los principales atributos del ser humano son la igualdad y la libertad, pudiendo ser ejercitados por estos; sostenía que los hombres vivían en condiciones pacíficas, todo lo contrario, a Hobbes. Un derecho natural es la tendencia a preservar la vida, integridad, familia y tiene la opción de elegir los medios para lograrlos respetándose entre sí.

A título personal puedo concordar y estar de acuerdo con Rousseau. El hombre nace bueno, sin manchas, sin egoísmo y sin maldad. Son otros elementos, que veremos adelante, los que han hecho que el hombre cambie su actitud de bien y prefiera o apetezca la actitud del mal.

\section{¿EI ser humano es bueno o malo por naturaleza?}

Una respuesta distinta a la pregunta planteada, es propuesta por Segrelles A., quien es citado por el Flórez, L. (s.f.), este autor, asegura que Segrelles afirma que el hombre nace malo y la sociedad lo corrompe aún más. Afirma Flórez que ninguno, ni Rousseau ni Segrelles, tienen la verdad absoluta; por un lado, pareciera que un niño trae las páginas en blanco, a expensas de la influencia social; por otro, pareciera que el niño comenzara ya a rendir culto al consumo.

Se puntualiza que el hombre no nace bueno o malo por naturaleza, la especie humana trae una herencia cultural; esta le potencializa a ser lo uno o lo otro, dependiendo de los fines del hombre y los medios para lograrlos (Flores, s.f.). 
Rousseau defendía que el hombre, a pesar de todo, nace bueno, viene con bondad, no trae ninguna maldad en su corazón, nace limpio de todas las cosas malas, posee una inclinación natural a la caridad, a la solidaridad. Cuando nació la propiedad, cuando alguien dijo: esto es mío, se iniciaron los problemas, se despertó la envidia y nació la competencia... nació la agresividad.

Durante la historia del pensamiento filosófico han existido diversas teorías en las que se afirma que intrínsecamente, los hombres nacen malos. Hobbes afirma que, en el estado natural, el hombre está alejado de la paz, que se ha convertido en lo que él llama "lobo contra hombre", y que está unido y participa en sociedad con el único objeto de sobrevivir. Kant también defendió esta posición y opinaba que se debería obligar a las personas a abandonar el estado de guerra y buscar la paz social, a este acto le llama: razón práctica.

Hoy día, es verídico afirmar que el hombre es su propio enemigo. La especie humana es la única que ataca premeditadamente y no por instinto; a diferencia de los animales, el ser humano sabe bien, en la mayoría de los casos, puede razonar lo que hará y aun así hace el mal (López, 2020).

\section{Rousseau contra Hobbes}

Si Hobbes defiende que las personas son inherentemente malas, Rousseau es todo lo contrario. Es más agradable que haya una tercera forma de afirmar que las personas tienen la capacidad de decidir si son buenas o malas. Freud pensaba de otra forma, se dio cuenta de que esos impulsos eran instintivos y afirmó que eran realmente necesarios.

Al respecto de todo esto, Reyes (2018) opina que, ante las dos posiciones, que parecen irreconciliables, establece que en la naturaleza humana existe lo que se necesita para ser bueno, como para ser malo. Como lo indica Freud, el hombre está compuesto tanto por el Eros, que simbolizaba el amor erótico y los impulsos de vida y el Tánatos, que representa la muerte y su pulsación; todo ello determinaría si el hombre se vuelve malo o bueno. De las proposiciones tanto de Rousseau como de Hobbes nacen corrientes de pensamiento; corrientes tales como el materialismo y el idealismo, de las que nacen después la izquierda y la derecha y sus variantes.

\section{El hombre es un lobo para el hombre}

Esta es una de las frases más destacadas de la obra "De Cive" de Hobbes. La frase no le pertenece porque se le atribuye al comediante latino Plauto. Aun así, es popular en su trabajo. Esta frase describe el egoísmo de las personas en el estado natural. Los hombres para Hobbes son egoístas por naturaleza y anteponen su propia supervivencia a la supervivencia de los demás. Por lo tanto, las personas cometen actos que afectan la vida y la paz de los otros. Desde esta perspectiva, Hobbes asume que las personas son malvadas, bárbaras o irracionales.

Rousseau señaló que el nacimiento de la sociedad trajo el nacimiento del país, y la primera ley no era más que un tratado social. 
Ahora, si una persona nace buena, habrá una pregunta, ¿por qué sale de eso? Si una persona es mala, ¿quiere dejar la sociedad para difundir su maldad? A partir de estas ideas, habrá otros problemas, por ejemplo, si la situación no es buena, ¿por qué tienes que hacer un buen trabajo si no lo haces en la naturaleza? Rousseau no niega la maldad de la humanidad, afirma que la humanidad es mala ahora, porque ha estado lejos de la naturaleza, fuera de su verdadero estado natural de bondad (Docta ignorancia, 2016).

Afirmar, que el hombre es bueno es algo limitado y peligroso; como lo es decir que el hombre es malo, pues sería la perfecta excusa para deshacerse de la responsabilidad por los actos cometidos.

Existen muchas personas malas en el mundo o dentro de la sociedad, sin embargo, también existen personas integras, rectas, incorruptibles. El hecho de generalizar nunca es correcto. Lo más prudente es pensar que hay de ambos lados involucrados y que, aunque no lo quisiéramos, no podemos evitar que exista el mal. Desde el punto de vista religioso, así como el frío es la ausencia de calor y la oscuridad es la ausencia de luz, el mal no existe, sino que es la ausencia de Dios en el corazón de las personas.

También hay gente buena y cuando uno de ellos se encuentra en sociedad es necesario que las personas íntegras perseveren, aprendan, respeten, imiten y mejoren. Cuando nos encontremos a alguno de ellos tenemos que seguir el ideal del que tanto habla Kant: "La perfección espiritual es lo que debemos perseguir".
Una persona puede mantener la integridad y no necesitar la ley; puede comportarse bien según sus propios principios, no por miedo al castigo; pero si toda la sociedad puede ser recta como esa persona, la honestidad sería posible, ya no será una utopía (Docta ignorancia, 2016).

\section{Conclusión}

Para que nuestra sociedad pueda existir sin leyes debemos cambiar todos, lo cual pareciera no ser tan probable, ni ser cosa fácil, pero cada uno puede no necesitar de leyes siendo recto, con valores y principios firmes e incorruptibles. Individualmente se puede cambiar y llegar a ser tan bueno para no necesitar leyes. El hombre nace bueno, sin deseos nocivos y sin malas intenciones, es el medio, la sociedad, las influencias que recibe lo que puede transformarlo, cambiarlo y convertirlo adoptando actitudes malas.

Para Rousseau lo que origina la maldad es el nacimiento de la propiedad. Esto inicia las disputas, la envidia, la inconformidad, los problemas, los conflictos y las guerras. Hobbes afirma rotundamente que el hombre es malo por naturaleza. Que no cambia, que no aprende y que solo persigue hacer daño, hacer mal. Los hombres buenos jamás necesitarán de leyes, son los malos y los malvados los que deben vivir bajo las disposiciones legales y bajo el imperio de la ley. 


\section{Referencias}

Carpintero, E. (2012). El bien y el mal son inmanentes en nuetsra condición humana. Revista Topía. Obtenido de Revista Topía: https:// www.topia.com.ar/articulos/mal-y-bien-son-inmanentes-nuestracondici\%C3\%B3n-humana

Comte, A. (2000). Invitación a la filosofía. Editorial Paidós.

Cortina, A., \& Emilio, M. (2008). Ética (Cuarta ed.). Ediciones Akal.

Docta ignorancia. (25 de septiembre de 2016). ¿El hombre es bueno o malo? Los buenos no necesitan leyes. Obtenido de YouTube: https:// www.youtube.com/watch?v=8mP4kAsoe8A

Flores Alarcón, L. (s.f.). ¿El hombre nace bueno y la sociedad lo corrompe? Los orígenes culturales de la motivación humana. Universidad Nacional de Colombia.

Gonzales Negrete, E. (2018). La reflexión política de Hobbes y Rousseau. Universidad Autónoma Metropolitana.

López Rodriguez, F. J. (2020). ¿La violencia tiene solución? Diario de León. Obtenido de https://www.diariodeleon.es/content/print/violenciatiene-solucion/202002191017101988294

Mora, J. F. (1979). Diccionario de filosofía. Montecasino.

Oxford. (2020). Diccionario léxico en español. Obtenido de Lexico.com: https://www.lexico.com/es/

Paiz, R. (2020). Comienzo y origen de la filosofía: el asombro. Revista Ciencia Multidisciplinaria Cunori, 163-170. doi: https://doi.org/10.36314/ cunori.v4i2.141

Rosental, M. M., \& ludin, P. F. (1965). Diccionario filosófico. Ediciones Pueblos Unidos. Obtenido de Filosofía.org. 
Utate, J. (2004). el ser humana desde la perspectiva bíblica y sus implicaciones para una filosofía . Instituto de Educación Cristiana .

Valdez, A. (2021). Conferencia enfoque socioformativo. (SFPU-DDAUSAC ) Obtenido de YouTube: https://www.youtube.com/ watch?v=5eaSMtJ-NCY\&t=3s

\section{$\triangle$ Sobre el autor}

Educador, poeta, escritor y periodista, Br. Industrial y Perito en una especialidad, PEM en Pedagogía y Ciencias de la Educación, Lic. en Pedagogía y Ciencias de la Educación, Licenciado en Pedagogía y Administración Educativa, Maestro en Filosofía. Egresado de la Escuela de estudios de Posgrado de la USAC. Profesor Titular de la Facultad de Humanidades. Ha publicado los siguientes artículos: "Comienzo y origen de la filosofía: el asombro" y "Diferencias y similitudes acerca del problema del deseo como causa de infelicidad".

Copyright (c) Rocael Paiz Varela

Este texto está protegido por una licencia Creative Commons 4.0.

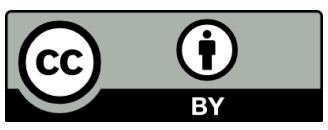

Usted es libre para compartir, copiar y redistribuir el material en cualquier medio o formato y adaptar el documento, remezclar, transformar y crear a partir del material para cualquier propósito, incluso comercialmente, siempre que cumpla la condición de atribución: usted debe reconocer el crédito de una obra de manera adecuada, proporcionar un enlace a la licencia, e indicar si se han realizado cambios. Puede hacerlo en cualquier forma razonable, pero no de forma tal que sugiera que tiene el apoyo del licenciante o lo recibe por el uso que hace. 